UCRL-JC-119411

PREPRINT

High Gradient Insulator Technology for the Dielectric Wall Accelerator

\author{
S. Sampayan, G. Caporaso, B. Carder, \\ Y. Chen, S. Holmes, E. Lauer, D. Trimble, \\ J. Elizondo, M. Krogh, B. Rosenblum, \\ C. Eichenberger, and J. Fockler
}

This paper was prepared for submittal to the 1995 Particle Accelerator Conference and International Conference on High-Energy Accelerators

Dallas, Texas

May 1-5, 1995

April 27, 1995

This is a preprint of a paper intended for publication in a journal orproceedings. Since changes may be made before publication, this preprint is made available with the understanding that it will not be cited or reproduced without the permission of the author.

PECEUMD

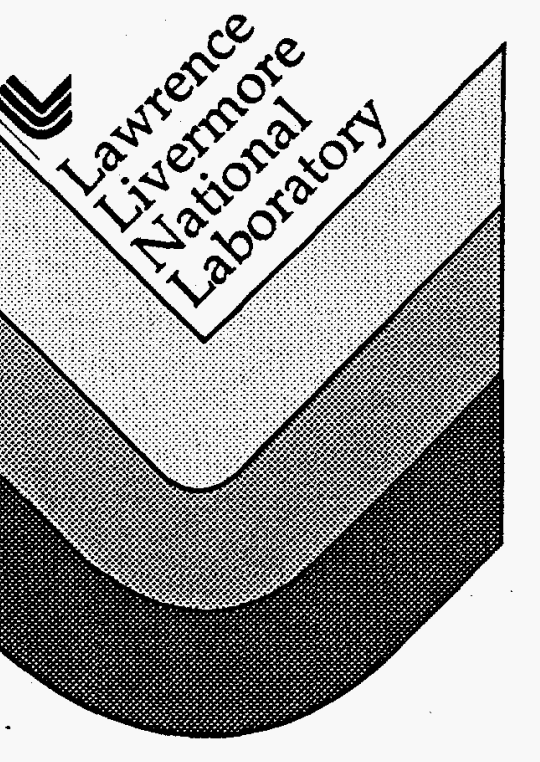

JUL 251995

OSTI 


\section{DISCLAIMER}

This document was prepared as an account of work sponsored by an agency of the United States Government. Neither the United States Government nor the University of California nor any of their employees, makes any warranty, express or implied, or assumes any legal liability or responsibility for the accuracy, completeness, or usefulness of any information, apparatus, product, or process disclosed, or represents that its use would not infringe privately owned rights. Reference herein to any specific commercial product, process, or service by trade name, trademark, manufacturer, or otherwise, does not necessarily constitute or imply its endorsement, recommendation, or favoring by the United States Government or the University of California. The views and opinions of authors expressed herein do not necessarily state or reflect those of the United States Government or the University of California, and shall not be used for advertising or product endorsement purposes. 


\section{DISCLAIMER}

Portions of this document may be illegible in electronic image products. Images are produced from the best available original document. 


\title{
HIGH GRADIENT INSULATOR TECHNOLOGY FOR THE DIELECTRIC WALL ACCELERATOR*
}

\author{
S. Sampayan, G. Caporaso, B. Carder ${ }^{()}$, Y. Chen, C. Holmes, E. Lauer, and D. Trimble, \\ Lawrence Livermore National Laboratory, Livermore, CA 94551 USA, J. Elizondo ${ }^{\text {b) }}$, Tetra Corporation, \\ 3701 Hawkins Street NE, Albuquerque NM, 87109 USA, M. Krogh, B. Rosenblum, Allied Signal \\ Aerospace KCP, Kansas City, MO 64141 USA, C. Eichenberger and J. Fockler, Pulse Sciences \\ Incorporated, 600 McCormick Avenue, San Leandro, CA, 94577 USA
}

Insulators composed of finely spaced alternating layers of dielectric and metal are thought to minimize secondary emission avalanche (SEA) growth. Most data to date was taken with small samples (order $10 \mathrm{~cm}^{2}$ area) in the absence of an ion or electron beam. We have begun long pulse $(>1$ $\mu \mathrm{s})$ high voltage testing of small hard seal samples. Further, we have performed short pulse ( $20 \mathrm{~ns})$ high voltage testing of moderate scale bonded samples (order $100 \mathrm{~cm}^{2}$ area) in the presence of a $1 \mathrm{kA}$ electron beam. Results thus far indicate a 1.0 to 4.0 increase in the breakdown electric field stress is possible with this technology.

\section{INTRODUCTION}

The dielectric wall accelerator (DWA) is a new accelerator concept particularly suited for short pulse $(<50 \mathrm{~ns})$ and high currents $(>1 \mathrm{kA})$. As we previously presented, the pulsed acceleration field is developed by a series of asymmetric Blumleins (i.e., pulse forming lines) incorporated into the insulator structure (Fig. 1) [1,2].

The maximum gradient of this accelerator is defined by the dielectric strength of the wall dielectrics and the maximum surface flashover electric field capability of the interior vacuum interface in the acceleration region. Solid insulator materials can typically meet the $20-30 \mathrm{MV} / \mathrm{m}$ requirement; the interface at the vacuum wall typically cannot.

High electric fields are possible with properly angled insulators. These insulators, however, are generally unipolar and are not optimum in the simplest configuration of the DWA (i.e., Fig. 1, where the electric field in the dielectric is always applied to the insulators). Thus we select a straight wall insulator as optimum.

*Performed under the auspices of the US Department of Energy by Lawrence Livermore National Laboratory under contract No. W-7405-Eng-48.

a)Consultant.

b)Present affiliation: Voss Scientific, 416 Washington Street SE, Albuquerque, NM 87108.

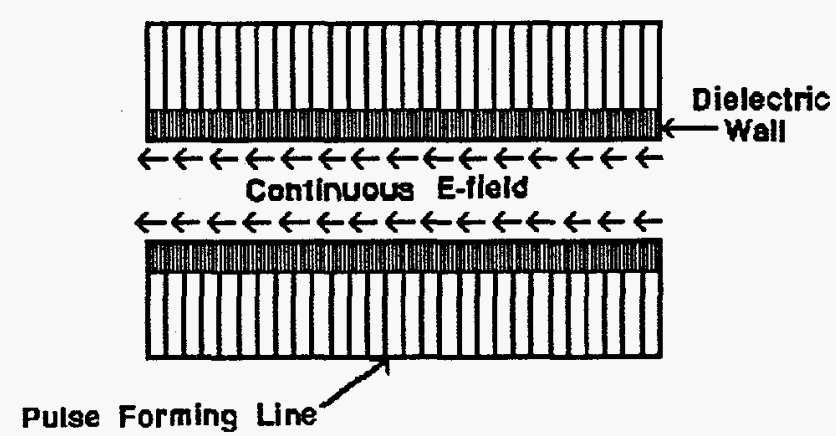

Figure 1. Dielectric Wall Accelerator (DWA).

Typical data for conventional straight wall vacuum insulators is shown in Figure 2. It is clear from this data, that to achieve the necessary gradients, alternate technologies should be investigated.

Improvements to existing technology can be made based on an understanding of the failure process. The most simplified vacuum surface breakdown model suggests that electrons originating from the cathode-insulator junction are responsible for initiating the failure [3]. When these electrons are intercepted by the insulator surface, additional electrons,

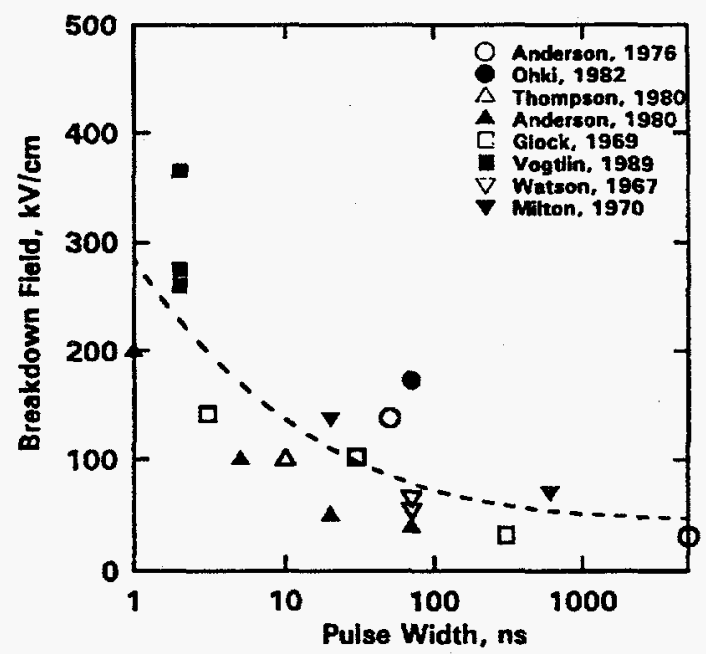

Figure 2. Breakdown thresholds for $0^{\circ}$ vacuum insulators. 
based on the secondary emission coefficient, are liberated. This effect leaves a net positive charge on the insulator surface, attracting more electrons and leading to escalation of the effect or the so-called secondary emission avalanche breakdown (SEA).

It has been shown that full evolution of the streamer discharge occurs within a fraction of a millimeter [4]. Placing slightly protruding metallic structures spaced at an equivalent interval is believed to interrupt the SEA process and allow the insulator to achieve higher gradients before failure $[5,6]$. This is the high gradient insulator concept being developed. When the DWA is combined with this high gradient vacuum insulator technology, short-pulse-high-gradients of greater than 20-30 MV/m may be possible.

\section{APPARATUS}

Several small sample (approximately $2.5 \mathrm{~cm}$ diameter by $0.5 \mathrm{~cm}$ thick) insulators were fabricated. The first was fabricated from interleaved layers of $0.064 \mathrm{~mm}$ stainless steel and $0.127 \mathrm{~mm}$ polycarbonate film. Two other small hard seal samples were fabricated from alumina and fused silica. The alumina sample was fabricated with $0.25 \mathrm{~mm}$ thick material and the fused silica sample was fabricated with $0.25 \mathrm{~mm}$ thick material. The interleaved metallic layers were formed by depositing gold on each planar insulator súrface by a sputtering technique and then bonding the stacked layers by heating while applying pressure. Concentricity was ensured by performing a finish grinding operation.

Small sample testing was performed in a turbo-molecular pumped, stainless-steel chamber at approximately $10^{-6} \mathrm{~T}$. High voltage was developed with a $10 \mathrm{~J}$ "mini-Marx". The Marx developed a pulsed voltage of approximately $1.3 \mu \mathrm{s}$, FWHM (3 $\mu \mathrm{s}$, base-to-base) and up to $250 \mathrm{kV}$ amplitude across the sample. Failure of the insulator was determined by a prompt increase in Marx current and a corresponding prompt collapse in the voltage across the sample.

Dimensions of the larger high gradient insulator were $14.5 \mathrm{~cm}$ I.D. by $22.1 \mathrm{~cm}$ O.D. by $2 \mathrm{~cm}$ length. The structure consisted of multiple kapton sheets layered and thermally bonded to form a single $45^{\circ}$ stepped conic section on the interior of the stack between each stainless steel grading ring. Spacing between each grading ring was 1-2 $\mathrm{mm}$. Supporting stainless steel flanges, bonded to each end of the insulator structure, provided mechanical attachment to the remaining structure.

Testing the larger, high gradient insulator structure in the presence of an electron beam was performed with a 1 MV, $20 \mathrm{ns,} \mathrm{oil} \mathrm{insulated} \mathrm{Blumlein} \mathrm{pulse} \mathrm{generator.} \mathrm{A} 2 \mathrm{~cm}$ diameter velvet emitter, bonded to an aluminum cathode support plate, was used to generate the electron beam. Unwanted emission in the area immediately next to the emitter was suppressed by applying a hard anodized coating.

Transport between the emitter and graphite collector was done by placing highly transparent (96\%) tungsten meshes in the beamline. These meshes locally short out the radial component of the electric field. Convergence then results from the self-magnetic field of the beam. Optimized placement of the meshes was determined using GYMNOS [7] and full transport required three meshes; one at the anode plane and two spaced at $12 \mathrm{~cm}$ and $21 \mathrm{~cm}$ from the cathode.

\section{EXPERIMENTAL RESULTS AND DISCUSSION}

Small sample high voltage testing results are tabulated in Table I. To obtain a particular data set, the insulators were subjected to several low voltage conditioning pulses. The voltage was then increased a small amount incrementally until breakdown occurred. Voltage was then reduced for several shots and then incrementally increased again until a consistent value resulted.

From this method, an ultimate flashover strength for the small samples of approximately $125 \mathrm{kV} / \mathrm{cm}$ for the alumina substrates, $200 \mathrm{kV} / \mathrm{cm}$ for the fused silica substrate and 200 $\mathrm{kV} / \mathrm{cm}$ for the polycarbonate substrate for a pulse width of 1.3

Table I. Small sample tests results

\begin{tabular}{cc}
\hline SUBSTRATE & BREAKDOWN FIELD \\
\hline Polycarbonate & $200 \mathrm{kV} / \mathrm{cm}$ \\
Fused Silica & $200^{\star 2}$ \\
Alumina & 125 \\
& \\
a) Type III anodized coating on electrodes \\
\hline \hline
\end{tabular}

$\mu$, FWHM, was measured. The trend in conventional technology (Fig. 2) for $0^{\circ}$ insulators indicates a breakdown threshold of approximately $50 \mathrm{kV} / \mathrm{cm}$. Thus, there was a net increase in the performance with these insulators over conventional technology of $2.5,4.0$, and 4.0 , respectively.

A similar scenario was used to determine the flashover strength of the larger high gradient insulator with and without an emitter installed. A total of 125 pulses at different voltages without the cathode installed were taken; 35 additional shots with the $2 \mathrm{~cm}$ diameter velvet cathode in place were also taken. These two tests were performed to deter- 
mine the effects of an emitter and electron beam in the vicinity of the insulator.

A slightly different manifestation of failure was observed in these tests (Fig. 3). For fields above $190 \mathrm{kV} / \mathrm{cm}$, we observed an increased collector current up to about $210 \mathrm{kV} / \mathrm{cm}$ when we observed late-time, fast transient currents and a decreased voltage pulse. Complete collapse of the voltage was not observed until about $250 \mathrm{kV} / \mathrm{cm}$. These observations lead us to believe that the primary failure mechanism resulted from strong explosive emission occurring in the vacuum gap.

Further manifestations of this effect is shown in Figure 4. Below about $210 \mathrm{kV} / \mathrm{cm}$, we observed currents consistent with the GYMNOS predictions. Above an electric field of $210 \mathrm{kV} / \mathrm{cm}$, we began to observe a strong trend away from this predicted current; $1.6 \mathrm{kA}$ compared with the predicted $1.1 \mathrm{kA}$ at $250 \mathrm{kV} / \mathrm{cm}$. We observed this ultimate threshold to be consistent with breakdown data taken in the absence of an electron beam.
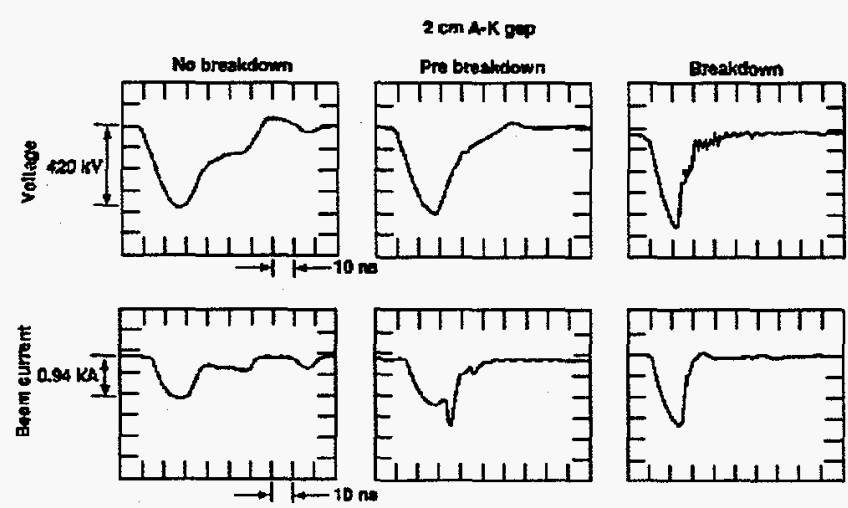

Figure 3. Typical pre-breakdown and closure pulses

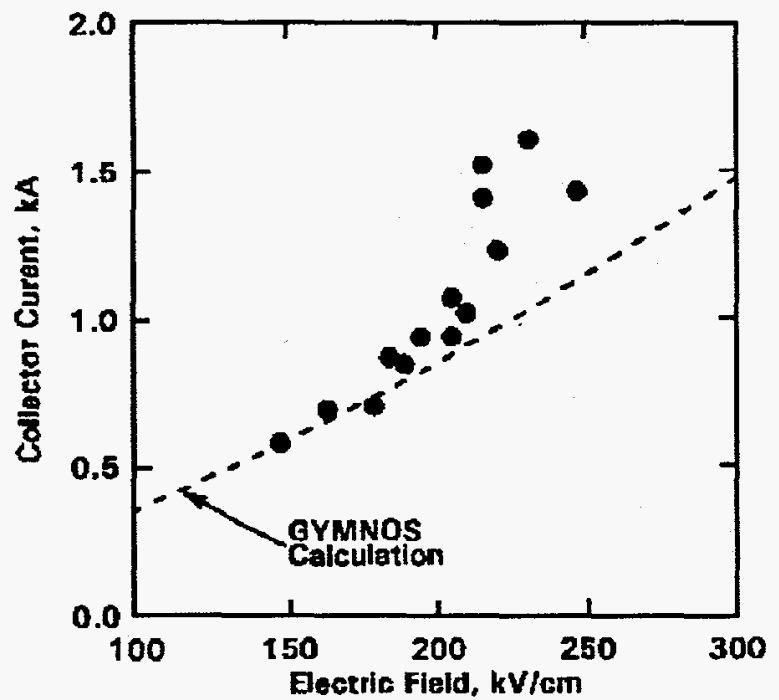

Figure 4. Comparison of predicted and measured currents.
Further physical evidence of this failure mode was observed upon opening the structure; we observed explosive emission sites, i.e. pitting on the stainless steel cathode structure supporting the insulator.

Further testing of this structure is planned. In these upcoming experiments, we intend to test the effects of explosive emission suppression coatings on the entire cathode electrode surface and the metallic gradient rings within the high gradient insulator.

\section{SUMMARY}

We began testing a new high gradient insulator technology. The insulator consists of finely spaced metal electrodes interleaved with the insulator substrate. The spacing of these metal electrodes is on the order of a streamer formation distance. For small samples, we observed significant improvement over conventional $0^{\circ}$ insulators subjected to long pulse fields. For moderate size insulators in the presence of an electron beam, we observed slightly reduced improvement but begin to observe the effects of explosive emission from the cathode surface.

\section{REFERENCES}

[1]G. Caporaso, presented at the 1994 Joint Topical Course "Frontiers of Accelerator Technology", Maui, Hawaii, 1994.

[2]S. Sampayan, et. al., presented at the 1995 Particle Accelerator Conference on High Energy Accelerators, Dallas, Texas, 1995.

[3] H. Miller, in Proceedings of 1992 15th International Symposium on Discharges and Electrical Insulation in Vacuum (Vde-Verlag Gmbh, Berlin, 1992), pp. 165-174.

[4]W. Glock and S. Linke, Laboratory of Plasma Studies, Cornell University Report No. LPS 24, 1969.

[5]E. Gray, Private Communication.

[6]J. Elizondo and A. Rodriguez, in Proceedings of 1992 15th International Symposium on Discharges and Electrical Insulation in Vacuum (Vde-Verlag Gmbh, Berlin, 1992), pp. 198-202.

[7] D. Hewett and J. Larson, Lawrence Livermore National Laboratory Report No. UCRL-ID-1 10499, 1992. 